\title{
EL CREPÚSCULO DE LA MENTE
}

THE TWILIGHT OF THE MIND

\section{RESUMEN}

En este artículo se comentan algunos ejemplos recientes del comportamiento autodestructivo y se hace un breve recorrido por algunas aproximaciones teóricas que estudian este aspecto del comportamiento humano. Tras hacer referencia a algunos estudios científicos, se analiza «La Pianista», la novela autobiográfica de Elfriede Jelinek (la actual premio Nobel de literatura). Partiendo de dicha narración en primera persona del sadomasoquismo y la automutilación, se analizan algunos aspectos claves en este tipo de pacientes como: la elección del cuerpo como campo de batalla, la relación entre conducta autolesiva y la alexitimia, su tendencia a la exoactuación y sus problemas de identidad, entre otros.

Palabras Clave: Automutilación, Sadomasoquismo, Elfriede Jelinek, Imagen corporal, Alexitimia.

\section{ABSTRACT}

In this article, some recent samples of self-destructive behaviour are commented on and a brief overview of some theoretical approaches which study this aspect of human conduct is given. After mentioning some scientific studies, «The Piano teacher», the autobiographical novel of Elfriede Jelinek (the current Nobel Prize for Literature) is analysed. On the basis of the earlier cited narration in the first person of sadomasochism and self-mutilation, some key aspects in this kind of patients such as: the choice of the body as a battlefield, the relationship between self-harmful behaviour and alexithymia, his inclination to act out their conflicts and their identity problems, among others, are analysed.

Key Words: Self-mutilation, Sadomasochism, Elfriede Jelinek, Bodily image, Alexithymia. 


\section{INTRODUCCIÓN}

«Se buscan hombres, jóvenes y robustos, de entre 18 y 30 años, para ser devorados». Este es el anuncio aparentemente inofensivo que colgó en Internet el apodado «Caníbal de Rotenburgo» hace un par de años. Como seguramente recordaréis, la víctima acudió voluntariamente a esa cita en la que por fin lograría lo que llevaba anhelando tanto tiempo: incorporarse al cuerpo de otra persona, en definitiva, dejar de ser él mismo.

Los forenses que examinaron al caníbal no encontraron en éste síntomas psicóticos. En cambio, no se descartaba esa posibilidad en la víctima, también se barajó la hipótesis de que padeciera algún trastorno de la identidad sexual. Es imposible determinarlo, dado que apenas hay información disponible. Sólo se sabe que había arreglado su testamento antes de participar en su última cena y que fue él quien impuso el ritual: él le pidió al caníbal que le cortara el pene y que lo cocinara para comérselo juntos. También se sabe que tardó 10 horas en desangrarse y no hizo nada para seguir vivo. Sea lo que fuere lo que se le pasó por la cabeza, lo que está claro es que su instinto de supervivencia estuvo aquel día totalmente eclipsado por su deseo de morir.

Este ejemplo superlativo de autodestrucción por medio de otra persona ilustra alguno de los aspectos que voy a tratar en mi presentación: el absoluto rechazo que sienten algunas personas respecto a su cuerpo y lo que, en mi opinión subyace a ese repudio, el desprecio a su subjetividad. Este aspecto llevado al extremo se traduce en algunos casos como el que acabo de comentar en el deseo de convertirse en una cosa (un alimento) para el otro.

Pero sin llegar hasta este punto se pueden observar en la clínica algunos fenómenos relacionados como pueden ser las conductas autolesivas, la automutilación o algunos trastornos de la imagen corporal como los trastornos de la alimentación o los trastornos dismórficos. Fuera de la clínica, y de una manera socialmente aceptada, tenemos a todas esas personas que se someten a intervenciones de cirugía plástica para «convertirse en otras personas». Un reciente estudio de Nancy Andreasen(1) pone de manifiesto que un porcentaje considerable de personas que se someten a dichas intervenciones podrían ser diagnosticados de trastorno dismórfico.

\section{LITERATURA CIENTÍFICA}

Algunos estudios científicos como el llevado a cabo en la Universidad de Providence por Zlotnick y colaboradores (2), encuentran correlaciones significativas entre las conductas autolesivas o automutilaciones con los trastornos de alimentación (más concretamente afirma que un $60 \%$ de personas con trastorno de alimentación se autolesiona), el trastorno de personalidad límite, trastorno de estrés postraumático y los trastornos disociativos. Además cita como características principales de estos pacientes su impulsividad y la dificultad para experimentar sentimientos o alexitimia. 
Las estadísticas muestran que la automutilación es más frecuente en mujeres. Un estudio llevado a cabo con 240 sujetos en la Universidad de Missouri (3) puso de manifiesto que la edad de inicio de esta conducta fue a los 14 años y que, con el tiempo, aumenta en frecuencia e intensidad ( $p . e$ de cortes superficiales en la piel se pasa a cortes más profundos). El $70 \%$ lo consideran una adicción y la gran mayoría de participantes manifestaban no sentir apenas dolor. Por el contrario decían obtener un alivio temporal de síntomas como pensamientos intrusivos, ansiedad y episodios de despersonalización.

En cuanto a los factores predisponentes se señalan; el haber sufrido abuso sexual o físico (o más frecuentemente violencia verbal continua, negligencia o falta de cuidados apropiados) y la incapacidad para tolerar y expresar sentimientos o alexitimia.

Un caso clínico que conjuga todos estos elementos es el descrito por Adekola Alao (4). Éste presenta el caso de una paciente de 23 años diagnosticada de trastorno de personalidad límite y trastorno de estrés postraumático que se mutilaba insertando una cuchilla en su vagina. Había sufrido abuso sexual y maltrato físico por parte de su padrastro y cuando cumplió los 17 se dedicó a la prostitución. Como he comentado, parece haber una relación entre el haber padecido abuso sexual o malos tratos físicos y las automutilaciones. No en vano, hay un mito griego que describe una situación parecida: Neptuno, Dios del Mar, después de violar a una mujer le concedió el deseo de la ablación de sus genitales para no poder ser violada de nuevo.

Aunque estos estudios aportan información muy útil, no nos dicen mucho acerca de la experiencia subjetiva y la naturaleza del dolor de estas personas. Por ello, para el resto de mi presentación me voy a servir de «La pianista»: la novela autobiográfica de la actual Premio Nobel de Literatura, Elfriede Jelinek (5): En la citada novela narra en primera persona las fantasías sadomasoquistas y el sufrimiento de la protagonista en su camino a la autodestrucción. Su versión cinematográfica es famosa por la cantidad de desmayos que causó la famosa escena de la automutilación genital.

\section{«LA PIANISTA»}

Erika Kohut, la protagonista de la novela, es una mujer de 38 años que vive con su madre en Viena donde trabaja como profesora de piano en el conservatorio. Hija de madre católica y padre judío, se dice en la primera página de la novela que cuando ella vino al mundo su padre salió de él. Al parecer, cuando ella nació su padre -músico- se psicotizó y, con el tiempo tuvo que ser internado en un hospital psiquiátrico, donde murió. Desde entonces, Erika ocupa en cierto modo el lugar dejado por su padre, incluso su lugar en el lecho conyugal.

En la novela, la madre no tiene nombre. Es tratada con honores de diosa por Jelinek quien se refiere a ella como «Madre», en mayúsculas. La relación madrehija está cargada de agresividad por ambas partes, y en algunos momentos da la impresión de estar fuertemente erotizada también. Son frecuentes las escenas en que la madre la humilla y la pega. Erika tampoco se queda atrás, en una escena la 
tira de los pelos y fantasea con guardárselos en el bolsillo para acariciarlos mientras da clase. También, se deja entrever que la madre de Erika solía golpear a su marido cuando éste enloqueció. El lema de la madre es que para evitar tener que cerrar las heridas que pueden causarle a su hija fuera de casa, prefiere infligirlas ella misma y luego encargarse de la terapia. Además, Erika fue educada por su madre para brillar más que el sol. Su madre inculcó el perfeccionismo en Erika, de manera que ésta no puede ignorar los errores al piano más nimios, los cuales la «aguijonean y la duelen durante meses».

La relación de Erika con su madre es muy ambivalente. La madre es necesitada y temida por igual. Pese a todo lo dicho, siente, sin embargo, la necesidad de estar cerca de ella aunque sabe que su abrazo la devorará y la digerirá completamente. Ella dice que a sus 38 años es un pez bien nutrido en el líquido amniótico de su madre. La carencia de distancia entre ambas a veces estremece, la escena que mejor ilustra esa relación anaclítica de dependencia de la cercanía del cuerpo de la madre es aquella en que, estando las dos en la cama, Erika se avalancha sobre su madre buscando refugio en su carne. Podría decirse que está atrapada en el abrazo de su madre, como muchos expertos dicen que le ocurrió a otro perverso ilustre, el escritor francés André Gide.

Toda la trama de la novela puede concebirse como un intento de Erika de escapar de la mirada de su madre. Al principio, parece que a través de sus perversiones sexuales y sus fantasías logra mantenerse a salvo de ella, escapar de su mirada, pero, si se analizan las fantasías más detenidamente, se observa claramente cómo su madre desempeña una función esencial en éstas. «No hay ninguna orden que Erika pueda dictar a su amante que no haya sido dictada ya por su madre».

Por otra parte, da la impresión de que Erika, por mucho que se esfuerce, no logra ser capaz de vivir del todo dentro de su cuerpo. Más bien parece que es la madre la que vive a través del cuerpo de la hija. Ni su lenguaje ni su deseo le pertenecen, ambos le han sido impuestos. Su madre se empeñó en que su hija sacrificara la vida por la música, hasta el punto de privarla del contacto con los niños de su edad para seguir practicando al piano. Además, desde niña le impuso un mundo simbólico que no la sirvió para desarrollar su subjetividad. Erika nunca compuso su propia música, el único lenguaje al que su madre la permitió tener acceso -el de las notas musicalesno la sirvió para expresar sus propias emociones, sino que su destino era interpretar música de otros, utilizar el lenguaje de otros. Ese universo simbólico impuesto que, por una parte, la controlaba desde que empezó a pensar y, por otra, la proporcionaba seguridad, era el pentagrama. Jamás pudo escapar de esas cinco líneas entre las que se sentía protegida y atrapada a la vez.

Desde el punto de vista del psicoanálisis, el lugar donde se ligan el lenguaje y el deseo es el cuerpo. Teniendo en cuenta que, como he expuesto anteriormente, ninguno de los dos son suyos del todo, no es de extrañar que su cuerpo la resulte 
completamente ajeno. Además, se da la circunstancia de que Erika fue educada para ignorar su cuerpo: el miedo más grande de su madre es que Erika lo escuche. Por las noches la madre se cuida de que las manos de su hija estén por encima de la sábana ya que éstas están exclusivamente destinadas a las teclas del piano. Dadas las circunstancias, parece lógico que el campo de batalla en el que se había de librar la guerra de Erika fuese precisamente su propio cuerpo.

\section{EL CUERPO COMO CAMPO DE BATALLA}

Algunos libros como «Cuerpos en estado de sitio» de Favazza (6) o algunos capítulos del libro de Karl Menninger «El hombre contra sí mismo» (7) describen casos de personas que le han declarado la guerra a sus cuerpos $y$, por extensión, al mundo al que, según la expresión de Heidegger, hemos sido arrojados.

Jean-Paul Sartre (8) afirma que establecemos contacto con el mundo a través del cuerpo. Para el filósofo francés, vivir corporalmente es lo que proporciona sentido de realidad o, lo que es lo mismo, una realidad con sentido. Es el cuerpo el que haciéndose espacio, tiempo y encontrándose con otros, hace real y habitable el mundo. Tratando de destruirlo, estas personas intentan destruir su vínculo con el mundo inmediato que les ha tocado habitar y que no pueden hacer nada para cambiar.

Muchos pacientes afirman que, cuando la situación externa no es susceptible de ser modificada, para no soportar el dolor que eso les produce, se provocan un dolor más manejable y soportable. Así por ejemplo, una paciente de nuestro grupo de trastornos de alimentación, comenzó a hacerse cortes tras la muerte de su madre cuando ella tenía 13 años. Dice no poder recordar nada del año que siguió a la muerte de su madre, sólo que se sentía muy impotente y que se sentía como un robot. Dice que comenzó a autolesionarse para saber si aún tenía sangre en las venas. Joyce McDougall en su obra «Los teatros del cuerpo» (9) dice que, los acting out sirven para confirmar la existencia de estas personas. Aunque pueda parecer paradójico esta paciente decía que la cosa que más miedo le daba es el dolor físico.

Ronald Laing en «El yo dividido» (10) describe personas que se experimentan a sí mismos como autómatas, robots o piezas de maquinaria. Estos sentimientos de irrealidad que tienen algunas personas respecto a sí mismos, el sentirse insustanciales o más muertos que vivos, son agrupados por este autor en el concepto de «inseguridad ontológica». Cuando la subjetividad de una persona ha sido drenada o no se ha desarrollado convenientemente, queda abierta la posibilidad de experimentarse a uno mismo como objeto de su experiencia. Uno se convierte, como le sucedió a Erika Kohut, en espectador de sí mismo y de su propia vida.

Jean-Paul Sartre en «El Ser y la Nada» (8) afirma que, en esas circunstancias, el acto mismo de experimentar al otro en cuanto persona es un acto suicida. Por esta razón, el alumno que quiere tener relaciones con ella (Walter Klemmer), representa 
una amenaza para ella. Él encarna el mundo de los sentidos, precisamente el mundo del cual ella ha sido excluída. Se siente amenazada por la posibilidad de convertirse en no más que una cosa sin vida alguna ni para sí misma ni para otro. Como más adelante expondré, recurre a sus perversiones para intentar no ser un objeto.

Otro concepto de Laing relevante para el asunto que nos ocupa es el de «Yo-no encarnado». La persona «encarnada» está totalmente en su cuerpo. Está envuelta en los deseos, necesidades y actos de su cuerpo; está sujeta a la culpa y la angustia que penden de tales deseos. Por el contrario, las personas que tienen el «yo-no encarnado» sienten su cuerpo como un objeto entre objetos. El yo-no encarnado contempla todo lo que hace su cuerpo sin comprometerse directamente.

Los estados transitorios de disociación del yo y del cuerpo ocurren incluso en personas sin patología. La disociación es una respuesta disponible para las personas que se encuentran encerradas en una situación amenazadora de la que no hay salida posible. El único escape posible es una retirada «hacia» uno mismo y «fuera» del cuerpo. Se siente que el cuerpo obra de forma automática y la persona se transforma en un observador que contempla con pasividad lo que está haciendo su cuerpo o lo que le están haciendo.

El individuo cuyo modo de ser-en-el-mundo posea esta naturaleza dividida, se halla viviendo en un mundo que encuentra amenazante y del que no hay salida posible. El yo deja de relacionarse directamente con el mundo exterior para implicarse, como dice Kierkegaard, en «una relación que lo vincula a uno mismo consigo mismo»(11).

El divorcio del yo respecto del cuerpo es doloroso pero también su medio de defensa básico. Es como si estos pacientes tuvieran que morir emocionalmente para que los sentimientos no los maten. Por así decirlo, una herida física hace las veces de torniquete psíquico.

Sartre en «El Ser y la Nada» (8) examina diferentes formas de fingir ante uno mismo que uno no está «en» lo que está haciendo. Las personalidades «as if» de Helen Deutsch, la noción de «falso self» de Winnicott o la personalidad sobreadaptada de David Liberman serían ejemplos de esta idea apuntada por Sartre.

\section{CUERPO COMO MATERIA PURA}

Como expuse anteriormente, algunos psicoanalistas defienden que el cuerpo es el lugar donde se unen el lenguaje y el deseo. El mayor miedo de la madre de Erika es que su hija escuche a su cuerpo. Cuando quiere castigarla verdaderamente, ni la humilla, ni la pega; simplemente la condena al silencio, deja de hablarla. De esta manera, a base de muchos minutos de silencio a lo largo de los años ha logrado que su cuerpo permanezca totalmente callado, especialmente en algunas zonas. Erika dice sentir «madera sólida en el lugar donde el carpintero hizo un orificio». 
Por otra parte, su madre y su abuela la privaron del contacto con otros niños. Cuando el cuerpo se aísla del mundo exterior o se atrofia o no se desarrolla convenientemente. Como dijo Goethe «Si el ojo no participara de las características del sol nunca podría llegar a mirarlo».

No es extraño, por tanto, que aparezcan en el cuerpo de Erika zonas mudas, zonas prohibidas. El suyo es un cuerpo mudo, pétreo, inerte, materia pura. Desde este punto de vista, se dice de un toxicómano necesita inyectarse deseo. La droga libidiniza, da vida, a su cuerpo desvitalizado. De la persona que se autolesiona podría decirse que sólo logra sentirse viva desgarrándose la piel. Paradójicamente, abriéndose una herida se intenta tapar un abismo aún mayor que se entreabre de repente. «Ese pulso con el abismo en torno al cual gravita la vida psíquica de una persona», tal y como apunta Colina en «Escritos psicóticos» (12), es llevado a cabo por Erika con la cuchilla de afeitar de su padre en la mano.

Una paciente dijo algo que ilustra bien este aspecto: «Necesito sentir algo en el cuerpo, llenar el vacío, por eso me pincho o me rajo». Cuando estas personas sienten ese vacío o falta de identidad recurren a ese tipo de acciones para poder estar en el mundo, aunque ese estar en el mundo sea estar «como si».

En otro orden de cosas, Erika siente que está encerrada por mandato de su madre dentro de un cuerpo en que «la naturaleza parece no haber dejado ni una sola abertura». Sólo puede salir de allí sangrando. En la escena en que se clava un cuchillo dice: «Un vacío se abre en el hombro de Erika. El acero ha entrado, ella ha salido». La visión que tiene de su figura es similar a la que retrata el escritor francés Louis Ferdinand Céline en «Viaje al fin de la noche» (13). Siente que es un «recinto de tripas» que la encierra. En sus fantasías, como más adelante comentaré, el cuerpo inerte e informe que ella siente que es, ansía tomar forma a base de latigazos y puñetazos.

\section{ALEXITIMIA: SORDOMUDOS DEL AFECTO}

El término fue introducido por Sifneos para referirse a la incapacidad de algunos individuos, para encontrar palabras o representaciones cognitivas que describan sus propios sentimientos (14). A estas personas, les resulta muy difícil ponerse en contacto con sus sentimientos.

Jaspers (15) habla también de un «torturante sentir un no sentir» que aparece al principio de todas las patologías y cuyo extremo es el autismo: la pérdida absoluta del contacto afectivo del paciente con el medio interno.

Joyce McDougall (9) habla de la diferente forma en que los psicóticos y los alexitímicos tratan el lenguaje: «El pensamiento del psicótico puede concebirse como una inflación delirante del uso de la palabra cuya meta es llenar espacios de un vacío aterrador; mientras que los procesos de pensamiento de los alexitímicos intentan vaciar la palabra de su significado afectivo». 
Pierre Marty (16) (introductor del término «pensamiento operativo») expone que cuando las expresiones simbólicas parecen demasiado peligrosas para el self, el lenguaje es obviado y el mensaje primitivo se expresa mediante el cuerpo. Con el acting out se trata de impedir que la representación de un acontecimiento doloroso, culpabilizante o amenazante llegue a la conciencia.

Joyce McDougall (9) denomina a estas personas «sordomudos del afecto». Ubica El origen de esta patología en la etapa preverbal en la cual habrían tenido lugar fuertes emociones. En esa obra, recoge varios casos clínicos de fusión madre-hijo, lo que ella denomina «un cuerpo para dos». En «La pianista» aparecen frases como «madre e hija unen sus cabezas, son una persona», las describe como «restos que solo pueden sentirse uno la una al lado de la otra». En esa etapa preverbal, existe una angustia arcaica ligada al temor de perder la identidad subjetiva. Ese temor es precisamente el caballo de batalla de Erika.

Respecto a la identidad, los teóricos cognitivo-conductuales actuales (17) retoman lo planteado por Skinner (18). Defienden que la identidad del yo tiene sobre todo una estructura narrativa. Destacan, por tanto, el esencial papel del lenguaje para la formación de la subjetividad. El «yo» es el sujeto en primera persona de las acciones que llevamos a cabo y de las sensaciones que nos llegan: Yo soy (fulano de tal), yo quiero (irme a mi casa), yo siento (frío, sueño...).... Recordemos que a Erika apenas se le ha permitido vivir ni en voz activa ni en primera persona. Para lograr sentir que es alguien, recurre en primer lugar a la voz reflexiva (hacerse cortes) y, por último, a la voz pasiva (ser pegada, ser violada). Ambos intentos, como luego veremos, serán en vano.

\section{LA TRISTEZA}

La tajante frase de Erika «No tengo sentimientos y, aunque los tuviera, nunca triunfarían sobre mi inteligencia» ejemplifican su tendencia a la intelectualización. Anna Freud dice que este mecanismo de defensa tiene por objeto la evitación sistemática de los afectos, mantenerlos a distancia (19). Más que no tener sentimientos, ha aprendido a no sentir para que los sentimientos no la maten. Como dice Pessoa, el poeta de la melancolía, «tuvo que olvidarse de sentir». El desgarrarse la piel actúa como el torniquete psíquico necesario para su supervivencia psicológica.

La tristeza de Erika más que expresarse con palabras, se hace carne. Su cuerpo siente que está muriendo, se siente en estado de putrefacción. En la novela las referencias al tiempo y la mella que hace en Erika son constantes. Al fin y al cabo, el cuerpo es el testigo directo de la decrepitud. Está absolutamente inmóvil, de luto por el cuerpo que un día fue. 


\section{EL MUNDO PRIVADO: ALGUNAS TEORÍAS DE LAS EMOCIONES}

Llegados a este punto, parece conveniente detenerse un momento en el ámbito afectivo. Voy a hacer un breve recorrido por algunas teorías de las emociones. Alguna de estas teorías explica por qué algunas personas sienten que no sienten.

Uno de los autores que más atención prestó al llamado mundo privado fue Skinner (18) que lo define como aquella parte del mundo «debajo de la piel» a la que sólo una persona tiene un acceso privilegiado. Este psicólogo enfatiza la construcción social del mundo emocional y resalta la importancia vital del lenguaje para la formación de la subjetividad.

Para este autor, la comunidad verbal de la que formamos parte configura a través del lenguaje una subjetividad interiorizada y autorreflexiva. La comunidad verbal nos enseña a observar nuestros estímulos privados mediante el reforzamiento de los enunciados que se refieren a ellos. Esos estímulos privados autoobservados constituyen la conciencia. Según Skinner, una persona criada en una comunidad que no reforzara las autodescripciones no sería consciente de nada, salvo de estar despierta. Además, lo que uno siente o debería sentir privadamente en diferentes circunstancias se define socialmente.

Parece lógico que en una persona como Erika Kohut que no ha sido estimulada por sus padres para prestar atención a sus sensaciones interiores, esta vida emocional esté infradesarrollada. Además, algunos estudios demuestran la existencia de alexitimia en los familiares de estos pacientes.

En otro orden de cosas, Marsha Linehan (20), especialista en el tratamiento de los trastornos límite, afirma que muchos de estos pacientes han crecido en ambientes en los que sus creencias sobre sí mismos han estado continuamente invalidadas, por lo que en su vida adulta presentan gran incertidumbre sobre sus sentimientos.

La teoría fenoménico-conductual de Heller (21) considera la emoción como una conducta en respuesta a una situación. En su obra «Teoría de los sentimientos», distingue entre el fondo y la figura de las emociones. Según él, el centro de la conciencia puede ocuparlo el sentimiento en sí o el objeto de dicha emoción. El sentimiento puede estar en primer plano (según esta terminología, sería la figura) o mantenerse como fondo del objeto. Por el contrario, cuando el sentimiento aparece como figura, los objetos de los sentimientos -objeto de amor, de miedo...- son relegados al fondo. Así, los sentimientos adquieren presencia y toman cuerpo, hasta el punto que se autoimponen como realidad psicológica y son corporalmente sentidos. De acuerdo con esta teoría, en las personas alexitímicas, los sentimientos permanecen en el fondo, aparecen en el foco de la conciencia con menos frecuencia que en otras personas que no presentan este rasgo.

Jean-Paul Sartre (22) considera las emociones como conductas. Según la teoría esbozada en «Bosquejo de una teoría de las emociones» se recurre a la emoción para disminuir, sustituir o rechazar una conducta que no se quiere o no se puede realizar. En este sentido, la emoción reemplaza a una conducta. Ambas son intentos de 
solucionar un problema. Mediante la emoción se intenta transformar el mundo. Cuando los medios disponibles son imposibles, la conciencia intenta transformar la situación. Sartre define la emoción como «una brusca caída de la conciencia en lo mágico». Cuando es imposible modificar el mundo con nuestra conducta, la conciencia tiende a transformar esa situación mágicamente, mediante la emoción, acercándose a los estados de conciencia propios del ensueño. Las personas alexitímicas no pueden recurrir a ese mundo mágico con la facilidad de las personas que no presentan ese rasgo. Desde este punto de vista, siendo la emoción lo que reemplaza a la conducta, no es de extrañar que recurran más a la conducta que otra persona, aunque esa conducta sea normalmente ineficaz para solucionar el problema en cuestión.

Sartre prosigue: «Para comprender claramente el proceso emocional (...) es preciso recordar el doble carácter del cuerpo, que es por una parte objeto en el mundo y, por otra, lo vivido inmediato de la conciencia». Da la impresión que estos pacientes se relacionan primordialmente con su cuerpo de la primera forma, y sus repetidos intentos de acceder a la segunda son un fracaso. En el caso de la pianista, se puede afirmar que ni siquiera cuando la pegan o se corta logra sentir su cuerpo vivo. Incluso en la escena final en que se clava un cuchillo justo encima del corazón dice «Ninguno de los terribles dolores esperados a cada segundo comienza».

\section{EL FRENO DEL ACTING OUT}

Como señala Freud, el paso a los procesos secundarios implica para el niño una reducción de la tendencia a obrar. Recordemos que los procesos secundarios están comprometidos con el principio de realidad y que este paso hace posible que la descarga de la energía pueda ser diferida.

Jean Piaget (23) señala la aparición del lenguaje como uno de los acontecimientos más importantes del desarrollo psíquico de una persona. Entre otros avances, da lugar a la interiorización de la acción. Esto hace que las conductas impulsivas del niño, se vayan sustituyendo por la conducta de reflexión. Esta conducta es el freno del acting out. Este concepto es recogido en los nuevos tratamientos del trastorno límite con el nombre de «mentalización» como el de Bateman y Fonagy (24). Con este término hacen referencia a técnicas que tratan de aumentar el insight de los pacientes.

Sin embargo, la pobreza de su mundo simbólico va más allá. En la novela apenas hay diálogos. Toda la trama se construye por medio de imágenes y fantasías de carácter predominantemente visual. De la protagonista destaca precisamente su habilidad de utilizar la mirada para escapar de la situación inmediata. No puede esconderse detrás de las palabras para ponerse a salvo.

Desde Kant, se ha conceptualizado el lenguaje como aquello que sirve para hacer del mundo un lugar habitable. Para Kant la palabra y las representaciones neutralizan la «cosa en sí», es decir aquello que es incognoscible y por tanto nos hace estremecer. 
Más tarde, Schopenhauer, dotó a esa cosa en sí de un carácter más dinámico, posteriormente Lacan lo caracterizó como algo que nos acechaba y podía venir hacia nosotros en cualquier momento. Cada uno de esos autores le dio un nombre distinto: la voluntad, la pulsión de muerte, lo real... Siguiendo ese planteamiento, el lenguaje es una especie de velo o de barrera que sirve para ocultar eso horroroso y desconocido que nos acecha oculto tras la pantalla de la realidad que conocemos, la realidad construida por las palabras.

Desde una perspectiva del lenguaje bien distinta, gran parte de las teorías de la psicología del pensamiento afirman que desde pequeños aprendemos a categorizar o agrupar los estímulos para organizar nuestra percepción, a cada categoría le ponemos un nombre. Si todo ese sistema se viniera abajo, no nos resultaría difícil imaginar el caos en que quedaríamos sumidos.

\section{DESDE LA LINEA DE BANDA (25)}

Para ilustrar este aspecto relativo al lenguaje, me voy a referir el discurso que Elfriede Jelinek preparó cuando recibió el premio Nobel. Es significativo que en una ocasión tan señalada enunciara un discurso sobre su difícil relación con el lenguaje. En ese discurso se queja de su perpetua lucha con las palabras. Dice que su lenguaje lucha por escapar de ella y, cuando se aleja, se lleva toda la realidad con él. Se lleva con él todas las representaciones de la realidad. Cuando esto ocurre, ella permanece en los márgenes, desde donde puede observar lo que sucede en la realidad. Al igual que su personaje se siente más una espectadora de su vida. Desde la línea de banda, que es precisamente el título de su discurso, observa la vida que siempre tiene lugar en otro lugar. Donde uno no está. Jelinek dice que todavía no ha muerto, pero ha traspasado ya la línea. Ella observa en soledad a los demás seres vivos desde la distancia.

Junto a ese margen en el que permanece está el vacío. Contempla a un lado la vida y a otro el vacío, sin osar adentrarse en ninguno de los dos. De esta forma tan gráfica, Jelinek ilustra la realidad existencial de muchos pacientes difíciles de encuadrar tanto dentro de la psicosis como dentro de la neurosis. Su lenguaje no se la ha roto del todo pero no la sirve para acceder a los demás (p.e cuando se corta repite sin cesar que está sola) ni tampoco para acceder a la realidad como argumenta Jelinek en su discurso. Su realidad se tambalea frecuentemente. De sus palabras se desprende que es consciente de la fragilidad de esa realidad construida por su lenguaje: «La tierra sobre la que estamos no es adecuada», "¿cómo se puede construir sobre un pozo sin fondo?»

¿Qué tiene para Jelinek de doloroso el lenguaje? Por una parte, se refiere a su necesario carácter imperfecto: siempre queda algo no dicho, algo que podría haberse dicho mejor, dice exactamente lo que habría sido mejor no decir. Como defendía Heidegger a propósito de los movimientos de avance y retroceso de la verdad, Jelinek dice que el lenguaje muestra $y$, a la vez, oscurece; revela y luego cubre otra vez el rastro que había dejado. 
Por otra parte, hace referencia a la tiranía de un lenguaje que no es del todo el suyo. Dice que ese «perro», que es como ella llama a su lenguaje, que se supone que está ahí para protegerla, reclama su obediencia. «El lenguaje sabe lo que quiere, yo no», «se atreve a adoptar ese tono de mando conmigo»... Estas parecen palabras propias de alguien que conoce bien la naturaleza del lenguaje: «Siempre ha sabido más que yo» 0 «Está escuchando secretos que se supone que yo no debo saber y los transmite». Parece que hay alguien que no es del todo ella que habla a través de sus cuerdas vocales. No es totalmente dueña de sus propias palabras. Para ella «la solución sería, querido lenguaje, que escucharas antes de hablar». La solución sería que nos adueñáramos completamente de nuestras palabras, pero eso supondría sortear la división propia del ser humano y seguramente nos adentraríamos en el terreno de la psicosis. Mientras tanto, como dice Jelinek, «el lenguaje seguirá repitiendo lo que le han recitado» porque «él es nuestro carcelero».

Este discurso, aparte de ser una diatriba contra la naturaleza del lenguaje, toma un cariz más personal cuando señala directamente a un culpable de esta situación: la lengua de su madre. Dice «Desde el principio, estaba en mí, pero ningún padre estaba», «El lenguaje de mi madre se ha quedado, mi padre se ha ido». En «La pianista» es la madre la que parece hablar por boca de Erika: «No hay ninguna orden que Erika pueda dictar que no haya sido dictada ya por su madre».

El lenguaje opera como un mago, disfraza las cosas para que sean soportables. El de Jelinek no está siempre a su disposición, se va cuando quiere, dejándola en medio de las cosas. Erika Kohut trata de tapar el silencio con el lenguaje de las notas musicales pero ese lenguaje no le pertenece: repite el de otros, le ha sido impuesto. Cuando su madre quiere hacerla daño la condena al silencio. Ante la insuficiencia de su lenguaje, inventa una especie de código que escribe sobre su cuerpo, un código que sólo ella entiende. Por así decirlo, su mano inscribe sobre su cuerpo el grito que su garganta se niega a pronunciar. Algunas personas que se autolesionan llaman «amiga» a su cuchilla, dicen que la herida es un profundo secreto que sólo se atreven a contarse a sí mismas.

\section{LA LUCHA POR SER SUJETO}

Según el filósofo Merleau-Ponty (26), el cuerpo es el único lugar donde se es sujeto y objeto a la vez. No es de extrañar que, siendo esa la lucha por excelencia de Erika, tenga lugar precisamente allí. Para Jelinek la subjetividad es un mito, una ficción. En la novela, Erika es tratada como un fetiche por su madre, como un objeto de su propiedad. En los únicos momentos en que la vemos ejercer como sujeto de la acción es cuando da rienda suelta a sus perversiones voyeuristas: cuando espía a las parejas teniendo relaciones sexuales, en las cabinas pornográficas... 
Su lucha por tener una identidad subjetiva toma forma concreta en su deseo de mirar, en lugar de ser mirada. Es precisamente en esos escenarios donde tiene lugar la subversión de los roles sociales: el deseo de mirar es típicamente masculino, normalmente es la mujer la que es mirada. En el caso de Erika, el objeto que es mirado se convierte en sujeto que mira. Pero es algo más que subversión de roles sociales, es su drama personal: huir de la mirada de su madre, quien la educó para ser un objeto de exposición destinado a ser mostrado en los recitales. La mirada es una prolongación del tacto (en su caso limitado al piano). En lo que se refiere a mirar, ha llegado a la cumbre de su sensibilidad. Pero no logra escapar de la mirada de su madre: en la novela se dice que Erika mira a sus alumnos con una mirada que cortaría el cristal, igual que su madre la miró el día que falló en el recital.

También aparecen roles invertidos en sus fantasías de ser violada. Es ella la que le dicta a un hombre cómo debe ser torturada y violada, en una muestra de dominación en la sumisión. Como dice Robert Stoller (27), es el masoquista el que dicta cómo de prieta debe estar la cuerda que le ata.

Al final, fracasa en su lucha por ser sujeto, ni siquiera logra ser sujeto pasivo: se da cuenta de que todas las órdenes que le dicta a Walter le fueron dictadas a ella por su madre. Las escenas en que se describe a Erika como un objeto inerte son abundantes. Pero es sobre todo en los brazos de Walter donde Erika se muestra como un cadáver más en acto que en potencia. Cuando está con él, nota que su cuerpo ya no es carne. Algo se encierra dentro de ella, «se convierte en un tubo de metal cilíndrico». Lo mismo ocurre en el cuerpo de él, ella lo fetichiza: en el momento en que se convierte en un cuerpo para ella, un cuerpo que puede ser tocado, se vuelve completamente abstracto para ella, pierde su carne. Cada uno se convierte en un medio para el otro, no hay relación recíproca entre dos personas, sólo goce autístico. Son mutuamente extraños. En esta situación, ella quiere desaparecer en él, ser devorada por él, no ser nada, como comentaba anteriormente sobre la víctima del caníbal.

Esta tendencia del ser vivo a volver al estado inorgánico, se corresponde con la noción de pulsión de muerte del psicoanálisis clásico. Se pone de manifiesto en los fenómenos de repetición, en el sadismo y el masoquismo, en las conductas autodestructivas... La novela ofrece un amplio catálogo de estos fenómenos.

\section{EL ESCENARIO: LAS FANTASÍAS}

Las fantasías son escenas susceptibles de ser representadas en forma casi siempre visual, el sujeto está siempre presente en ellas. En las fantasías son posibles las permutaciones de papeles, esto posibilita la identificación con el agresor frecuente en estos trastornos. 
El filósofo francés Bataille dice a propósito de los personajes de Sacher-Masoch que las víctimas hablan con la hipocresía propia de un verdugo (al fin y al cabo, son verdugos de sí mismos). Por el contrario, respecto a los personajes del marqués de Sade, dice que su lenguaje es esencialmente el de una víctima, afirma «sólo las víctimas pueden describirnos las torturas» (28).

En el masoquismo las fantasías son normalmente de suspensión. Además, los rituales de suspensión física como estar colgado son habituales. En palabras del filósofo francés Gilles Deleuze (28), estas personas están suspendidas en el dolor esperando el placer. No es que encuentre placer en el dolor, sino que el dolor o la humillación son condición indispensable para obtener el placer.

Para algunos autores como Daniel Lagache (19), el sadomasoquismo no solo está ligado a la relación sexual, sino que para él la relación del tipo dominio-sumisión es la dimensión fundamental de la relación intersubjetiva e intrasubjetiva. En el caso de la relación de Erika consigo misma, podría decirse que espera que su vida comience suspendida en el dolor de ser consciente de que su cuerpo va muriendo. Como si no tuviera derecho a vivir sin provocarse dolor, sin morirse un poco primero.

La función de la fantasía es poner el deseo en escena, en una escena en la que lo prohibido juega un papel protagonista. Normalmente siempre se repite la misma escena, es una escena que se para en un punto. Son escenas fijas, inacabadas: látigo que no acaba de desgarrar la piel, golpes que no acaban de llegar al estómago...

Stoller (27) afirma que las parejas sadomasoquistas fijan unas reglas de manera que puede afirmarse que se hacen menos daño que muchas parejas llamadas «normales». Erika confiesa al final que la aterra ser pegada. Cuando Walter lee la carta en que Erika especifica cómo quiere ser torturada, Walter dice que lo que se lee entre líneas es «Por favor, no me pegues». Podría ser que en su caso, la perversión cumpla una función protectora.

Dentro de la corriente psicoanalítica, algunos piensan que esta fantasía que tiende a repetirse -fantasma- siempre se para en el mismo punto debido al terror que les produce la escena que va después. La fantasía en que está encerrada en un pasillo estrecho por el que se tiene que arrastrar aparece varias veces en la novela. Ese pasillo no tiene aberturas, apenas hay espacio, no tiene puerta. Ella escucha los pasos de un hombre que se acerca cada vez más, pero no puede atraparla porque no hay puerta por la que pueda entrar al lugar donde ella está...

En cuanto al significado de las fantasías de violación, algunos autores destacan la presencia de este tipo de fantasías en personas que han sido violadas. Otros autores sugieren que son una ruta alternativa de sus supuestamente inapropiados deseos sexuales.

Al principio de la novela Erika afirma que solo en sus fantasías está a salvo de su madre. Pero cuando le desvela su secreto a Walter, le explica que su fantasía suprema es estar atada cerca de su madre, pero inaccesible para ella. Parece que la fantasía de Erika implica un deseo de castigar a su madre forzándola a presenciar su transición a la sexualidad genital, teniendo sexo con Walter. Para algunos autores de corriente psicodinámica esto puede leerse como una especie de reverso de la escena primaria. 


\section{LA REESCRITURA DEL UNIVERSO}

Sartre afirmó: «El proyecto fundamental del ser humano es ser Dios». Este aspecto tiene un papel protagonista en las perversiones en que me voy a detener. Janine Chasseguet-Smirgel en «Ética y estética de las perversiones» (29) concibe las desviaciones de la conducta sexual como un intento de reescritura del universo. Así por ejemplo Stekel describe el caso de un fetichista que escribía una biblia al revés.

Las perversiones de Erika incluyen: voyeurismo, erotismo uretral (obtener placer en la micción), masoquismo y sadismo. Para Freud, el niño es un «perverso polimorfo» porque obtiene satisfacción sexual de la satisfacción de las funciones corporales no ligadas directamente con la relación sexual genital. De hecho todos sus intentos de relación genital normal fracasan.

Otro ejemplo de conducta perversa en el que se puede apreciar este «querer-serDios» es por ejemplo el Calígula retratado por Albert Camus (30). Calígula sólo quería hacer posible lo imposible. Soñaba con tener la luna. Calígula pretendía destronar a Dios, se travestía de Venus. Siendo Dios podría cometer incesto con su hermana.

También en Sade puede apreciarse esta característica (29). Éste emprende una lucha contra la Naturaleza y contra Dios «por la tristeza en que nos sumió». El discurso de la naturaleza, nos advierte Sade, nos dice que nuestro padre o nuestra madre no son más preciados a los ojos de Dios que el del último de los gusanos que se arrastra por la faz de la tierra. Por esta razón, los personajes sadianos destronan a Dios. También en «La pianista», en la escena de automutilación genital, dice que quiere separar lo que Dios o la Naturaleza ha unido.

El telón de fondo de todas las perversiones es la transformación de la realidad, en Erika se focaliza sobre todo en su lucha contra el tiempo: ella busca una vuelta hacia atrás en el tiempo, «un orden cronológico trastornado». También los personajes sadianos tratan de destruir la realidad para crear una nueva. Niegan la muerte en tanto que fin absoluto.

Freud expuso en «Neurosis y psicosis» (31) que: «en la neurosis no se niega la realidad, simplemente no se quiere saber nada de ella, en la psicosis se niega y se busca reemplazarla». La perversión se concibe como una «locura parcial», se niega parte de la realidad. El perverso encuentra la manera de escapar de los sufrimientos del neurótico sin romper los lazos con la realidad. Se crea un universo extrayendo sus materiales de elementos de su mundo interno, lo rellena con sus propias ficciones, porque las ficciones del neurótico son insuficientes para él.

\section{TRANSGRESIÓN}

El autor que más atención prestó a la transgresión fue el filósofo francés Foucault. Para algunos críticos literarios la automutilación de Erika es una muestra de lo que Foucault llamó «Contra-discurso»: un intento de forjar una subjetividad alternativa 
a la propuesta por la cultura dominante. Es como si, dirigiéndose a los miembros de la sociedad patriarcal, les estuviera diciendo «¿Queréis que esté castrada? Pues aquí lo tenéis». Tras salir del cuarto de baño, su madre confunde la sangre de Erika con la menstruación, nuevamente la lectura como contradiscurso es también posible: «¿Queréis que sangre? Pues lo haré» (32).

Desde otra perspectiva, puede entenderse también como un ataque velado contra su madre. Durante toda la escena, su madre la llama para cenar. Da la impresión de que ella dirige contra sí misma los reproches que no osa dirigir contra su madre.

\section{CRÍTICA SOCIAL: LA CARENCIA DE IDENTIDAD}

Los personajes de Elfriede Jelinek reflejan la imposibilidad de la individualidad y la identidad en la sociedad contemporánea. Para la escritora austriaca, todo es repetición e imitación, todo se ha convertido en una imagen superficial, hasta el punto de afirmar que no existe nada bajo la superficie. Por eso, Erika Kohut, harta de vivir en el mundo de las apariencias, siente la necesidad de ver películas pornográficas en que se muestra lo auténtico de las personas: celulitis, granos, arrugas... Al final, triunfan las apariencias: Walter, que representa el mundo de las apariencias viola a Erika y al día siguiente, actúa con ella como si no hubiera pasado nada.

El discurso de la sociedad capitalista en que vivimos es el de la sacralización de los objetos: los objetos tiranizan a los sujetos, los cuerpos mismos entran en el mercado de los objetos. Algunas películas como «El último tango en París» (33) o «Intimidad» (34) describen las vidas de personas que se unen en un apartamento precisamente para dejar de serlo. En «El último tango en París» el personaje interpretado por Brando pone como única condición el no tener nombre. Como cité al principio a propósito del caso del caníbal alemán, aunque en ese caso se llevó hasta sus últimos extremos, el sujeto se coloca en la posición de un objeto de consumo, se consumen el uno al otro. Lejos de establecer un vínculo social como en una relación afectiva, se proponen un goce autista, cada uno goza por separado.

\section{LA FUNCIÓN DEL SÍNTOMA}

Volviendo al terreno de la sintomatología, voy a dedicar unas líneas a las funciones que cumplen estos síntomas.

\section{Función de las conductas perversas}

Para Robert Stoller, las conductas sexuales perversas representarían un intento de librarse de un sentimiento de humillación experimentado en la infancia (35). En esta línea coincide con Heinz Kohut (36) quien en su análisis de las patologías narcisistas destaca la importancia de un sentimiento de humillación muy marcado en este tipo de pacientes. 
Stoller (35) considera la agresión como el factor básico común a todas las perversiones, una agresión que permita al sujeto vengarse del daño sufrido en la infancia. En relación al sadomasoquismo, tal y como expone en "Dolor y pasión», algunas personas empezaron a desarrollar ese tipo de fantasías para escapar de una situación de dolor físico de la que era imposible escapar realmente. Se produce en estas personas un proceso de erotización del sufrimiento. Esto es compatible con la explicación que aportan las teorías del aprendizaje sobre las parafilias: por un proceso de condicionamiento, se produce una asociación entre el dolor y el placer sexual. En la novela, Erika dice que para ella el placer sexual está ligado al miedo, siempre que aparece uno, el otro no puede andar demasiado lejos.

Otto Kernberg (37) afirma que el afecto principal de la perversión es el odio. De esa manera, los biógrafos de Sade hablan de un intenso odio de éste a su madre, de ahí su intenso odio a los valores matriarcales. Un ejemplo de esto aparece en las palabras de una paciente que se autolesiona «Me conforta pensar que me vean muerta», de estas palabras se desprende cierto deseo de venganza subyacente.

La dinámica perversa, expone Kernberg, es circular: por una parte se busca la venganza, la destrucción del objeto; por otra, paradójicamente, ese objeto es necesitado y deseado. Esta dinámica se observa en la relación de los maltratadotes con su pareja.

\section{Función de las autolesiones}

Para tratar esta cuestión, hay que plantear una clasificación de los diferentes tipos de autolesiones, ya que es previsible que según el tipo cumplan una función diferente.

- Las autolesiones estereotípicas como golpes en la cabeza repetitivos se dan sobre todo en deficientes, autistas o pacientes del síndrome de Gilles de la Tourette. No hay un acuerdo unánime acerca del significado o función de estas conductas, pero muchos autores coinciden en afirmar que estos pacientes tienen un umbral sensorial más elevado, por lo que los golpes serían una forma de autoestimulación.

- La autolesión superficial o moderada: en esta categoría se incluyen cortes, quemaduras, excoriaciones en la piel, abrir viejas heridas... El efecto que refieren tener estos pacientes es un efecto calmante.

- La automutilación: es menos frecuente. En esta categoría se incluyen la castración, enucleación de los ojos, arrancamiento lingual... Aparte de algunas prácticas culturales como la ablación, esta conducta aparece en algunos pacientes psicóticos, en algunas personas con trastorno de identidad sexual y en pacientes con trastornos severos de la personalidad (especialmente el trastorno límite) al que luego volveré a referirme.

En cuanto a los pacientes psicóticos que se automutilan, algunos autores destacan el aspecto simbólico de estos actos (p.e. arrancarse los ojos para no seguir viendo). En esta línea, Bruno Bettelheim dedica su libro «Heridas simbólicas» a este tema (38). 
Para Chasserget-Smirgel, el acting out tiene por objeto el evitar la elaboración psíquica de los problemas (35). Un ejemplo de esto es cuando Erika recuerda una vez en que se equivocó tocando el piano y su madre la pegó en la mano, inmediatamente, para interrumpir el recuerdo, se clava alfileres en la mano y debajo de las uñas, impidiendo que el sentimiento de culpa apareciera en el campo de la conciencia.

Dentro de la teoría cognitivo-conductual, Favazza define estas conductas autodestructivas como una forma de afrontamiento que sirve para regular el afecto, reducir tensiones o acabar con un episodio disociativo (3). Proporciona un alivio rápido, pero temporal. Así, por ejemplo, una paciente afirma que cuando no sabe cómo solucionar un problema se corta y se dice «No pasa nada, es sólo un corte, un poco de sangre».

Dentro de esta corriente otros autores destacan otras funciones: aliviar un dolor emocional intenso, escapar sentimientos de confusión o de vacío, recuperar el control sobre su cuerpo, sentir unidad, respuesta a un intenso sentimiento de culpa, evitar un dolor psicológico mayor y menos soportable...

Favazza ha elaborado la llamada «Hipótesis del escape» para tratar de explicar algunas conductas como las autodestructivas, los atracones de comida, el consumo de tóxicos y los intentos de suicidio «en cortocircuito». Según este autor, estas personas encuentran muy aversiva la conciencia de sí mismas y buscan escapar de ella. Estas conductas responderían a un deseo de escapar a la autoconciencia. Durante esos episodios se produce un salto o estrechamiento cognitivo: se focaliza la atención solo en las sensaciones corporales inmediatas, no dejando así espacio en el campo de la conciencia para pensamientos intrusivos, sentimientos de culpa...

El modelo tiene particular importancia puesto que en él se basa el único tratamiento específico que existe para estas conductas: el programa SAFE, que se aplica en Berwyn, Illinois. También han demostrado su eficacia en la reducción de este tipo de conductas autolesivas la terapia dialéctico-conductual de Marsha Linehan, Terapia focalizada en la transferencia (llevada a cabo en la Universidad de Cornell, liderada por Otto Kernberg) y la terapia que Bateman y Fonagy llevan a cabo en el Hospital de Día de Halliwick (Reino Unido).

\section{TRASTORNOS LÍMITE}

Bajo este epígrafe se incluyen algunas patologías limítrofes con la esquizofrenia.

Para Kernberg las conductas autodestructivas aparecen dentro del espectro de las patologías masoquistas. Recordemos que el masoquismo no tiene solo una connotación sexual. Así la noción freudiana de masoquismo moral se refiere a la búsqueda de algunos sujetos de la posición de víctima, debido a un sentimiento de culpabilidad inconsciente (p.e una paciente de 18 años que dice que se acuesta con personas de mucha mayor edad que la repugnan, lo que la hace sentirse culpable después). Para Kernberg, los llamados «síndromes masoquistas» pueden aparecer en el nivel neurótico 
de la personalidad (p.e. enamoramiento masoquista) y, sobre todo, en el nivel límite o fronterizo de la organización de la personalidad. Esta organización o estructura de la personalidad es un concepto más amplio que el «trastorno de personalidad límite» que aparece en los manuales de clasificación diagnóstica al uso (35).

Otro autor que recoge en sus teorías algunos aspectos que han aparecido a lo largo de mi presentación es Zilboorg que acuñó el término de «esquizofrenia ambulatoria»para el diagnóstico de personas que sufrían episodios psicóticos transitorios en situaciones de gran carga emocional. Para Zilboorg, estos pacientes se caracterizaban también por tener intereses sexuales anómalos, esencialmente de naturaleza sadomasoquista. En esta línea, Helen Deutsch dentro de las personalidades «as if», incluye a aquellas personas que llevan una vida aparentemente normal, pero destacan por su aparente ausencia de sentimientos y falta de identidad. Para Deutsch estas personas tendrían características prepsicóticas. También, Hoch y Polatin incluyeron bajo el epígrafe de «Esquizofrenia pseudoneurótica» a las personas que se caracterizaban por una fuerte distorsión en el sentido del self y la imagen corporal. Por último, Sandor Rado habla del «déficit propioceptivo» de los pacientes esquizotípicos, que se caracterizan, entre otras cosas, por su conciencia distorsionada del self corporal (39).

En otro orden de cosas, Marsha Linehan (desde una aproximación cognitivoconductual) dice a propósito de Kernberg, que para éste la ira y el odio son las principales emociones subyacentes a esta patología. Para ella estas emociones son el producto de la incapacidad de estos pacientes de aceptar la realidad tal como es. Linehan aboga por el enriquecimiento recíproco de ambas teorías, por muy diferentes que puedan parecer a simple vista.

\section{EL CREPÚSCULO DE LA MENTE}

Por último, para ilustrar la situación de este tipo de pacientes difíciles de encuadrar tanto en el terreno de la psicosis como el de la neurosis, voy a utilizar la descripción que hizo la propia Jelinek a propósito del estado mental de Erika. Ésta se identifica con los primeros momentos del declinar mental de dos figuras de la música clásica que enloquecieron: Franz Schubert y Robert Schumann. Se identifica no con el Schumann cuyos pensamientos ya le habían abandonado, sino con el Schumann justo antes de llegar a este punto. Jelinek, cuyo padre músico murió en un psiquiátrico, dice que hay muchos matices, muchos tonos intermedios entre el gris y el negro. Erika, está recorriendo lentamente esa distancia que la separa de la nada. La escritora describe a la pianista como alguien que va oscureciendo sin darse cuenta, sin llegar a la apoteosis final de la desaparición de la consciencia.

El filósofo alemán Theodore Adorno (40), llama a ese momento de la vida de Schubert «El crepúsculo de la mente». Se refiere a esa fase en la que él sabía lo terrible que sería la pérdida de sí mismo antes de ser totalmente abandonado. En esa fase se aferraba a toda costa a los restos de él mismo que se estaban desvaneciendo poco a poco. 
La elección de esos dos autores no es casual. Schubert llevaba un estilo de vida que muchos calificarían de autodestructivo. Los críticos musicales dicen que hay un aspecto distintivamente mecánico 0 , si se prefiere inorgánico, en la repetición propia de la obra de ese autor -que es precisamente la que Erika interpreta en toda la novela-. El filósofo alemán, Adorno, destaca la trágica conciencia de la muerte en su última etapa, su obra está plagada de silencios interpolados como súbitas apariciones de una muerte inminente. Podría decirse que su obra final es un paseo por un paisaje desértico devastado por la muerte, no por su propia muerte, sino por la Muerte en si, con mayúsculas. Es música con una conciencia de vacío. Erika deja entrever que ha contemplado ese paisaje desértico que ofrece al espectador una inusual panorámica del vacío y de la plenitud al mismo tiempo, cuando afirma que ningún crítico musical entiende realmente el Réquiem de Mozart, ya que este es un himno a lo indeterminado, a lo inefable. Algo que ella parece conocer muy de cerca.

El desierto helado aparece también en sus fantasías. Aparece un paisaje helado que crece en la distancia, un paisaje sin camino, sin castillo donde refugiarse. Esta sola y asustada en medio de esa tierra baldía... Sin embargo, surge inmediatamente la fantasía del pasillo estrecho, como si esta fantasía tuviera para ella una función protectora de la que no pudiera prescindir.

En su universo simbólico el lenguaje musical desempeña un papel protagonista. Ya hablé antes de esas cinco líneas impuestas por su madre que controlaban su vida. Aunque parezca contradictorio, solo entre esas líneas encuentra seguridad. A ella no se la ha roto el lenguaje como le ocurrió a Schumann, pero tampoco le sirve ni para acceder a los demás ni a sus propios sentimientos. Respecto a Schumann, cabe recordar que empezó escuchando el do dentro de su cabeza. Luego al do se le añadió el fa sostenido. Unos días después comenzó a escuchar una orquesta dentro de su cabeza, él creía que era Mendelsohn que le enviaba mensajes musicales. Por último, las voces angelicales que le impelían a tocar música celestial se transformaron en alaridos de hiena.

Si la comparamos con Nietzsche (41), alguien que sí se adentró en ese desierto en el que, utilizando sus propias palabras, «las piedras son más piedras que antes» vemos que Erika es una experta en detener el pensamiento ante los primeros destellos de las tinieblas (cosa que el filósofo hubiera criticado duramente) ya sea haciendo surgir una de sus fantasías o llenando su vacío con un acting out. Pasea de puntillas en el mundo de los desechos y objetos muertos, pero no acaba de dejarse deslumbrar por el brillo de la oscuridad. No llega a «morir de inmortalidad»como el filósofo, tras vanagloriarse de haberse soltado de los grilletes que le sujetaban a la realidad. Más bien su cuerpo es demasiado consciente de estar muriendo. De ahí la enorme tristeza de la pianista, que necesita escuchar sus propios estertores para sentirse viva.

Por otra parte, la ya póstuma Erika tampoco logra escapar de su cuerpo muerto como hizo el filósofo. Algunos biógrafos afirman que Nietzsche enloqueció al identificarse con Zaratustra, «al ser visitado por la sombra del superhombre», trascendien- 
do así de su estatus de hombre mortal. Así, en «Así habló Zaratustra» (42) afirma: «Zaratustra ha superado la gran repugnancia por el hombre, el hombre es no-forma, materia bruta, piedra mal desbastada que espera un escultor» 0 "i $\mathrm{Y}$ he aquí que mi martillo se desencadena cruelmente contra la prisión de esta imagen! (...) Astillas de piedra vuelan pulverizadas».

Cuando habla de la locura de Schubert o del Réquiem de Mozart, parece hablar como alguien que ha sentido sobre su piel el soplo del espacio vacío. Sin embargo, aunque intuye el abismo, logra aplazar esa visión con un trozo más de carne desgarrada. No quiere morir aplastada bajo el peso de ese infinito denominado cosa, pulsión, repetición, vacío, lo real...

Aunque no llega a ser mártir en la cruz del pensamiento -como dice Thomas Mann de Nietzsche- tampoco logra acoplarse del todo a la cruz del neurótico. Según Alfred Adler, el neurótico está clavado en la cruz de su ficción. Nuestra vida se asienta sobre una serie de ficciones. En «La filosofía del como si», Hans Vaihinger (43) explica que vivimos con la creencia de que el mundo (con nosotros y nuestros seres queridos dentro) estará aquí mañana, como si conociéramos en su totalidad lo que es bueno y malo, como si hubiera un cielo o un infierno... Todos estos supuestos sobre el futuro guían nuestro presente.

Erika no puede preocuparse por el futuro porque ni siquiera puede creer en el presente. Su auténtico drama es no poder creer en lo que ya es. Su sufrimiento guarda muchos paralelismos con el de Fernando Pessoa, el poeta de la melancolía, que definía su drama como la melancolía de no sentir, no vivir, no ser «No soy nada», « ¡Si al menos enloqueciese de verdad!, pero no, es este estar entre, estar casi... Un interno en un manicomio es al menos alguien» (44)

\section{BIBLIOGRAFÍA}

1. Andreasen, N.C.; Bardach, J., «Dysmorphobia: symptom or disease?». Am J Psychiatry, 1977, 134, p.p. 673-676.

2. Zlotnick, C.; Shea, M.T.; Pearlstein, T.; Simpson, E.; Costello, E.; Begin A., «The relationship between dissociative symptoms, alexithimia, impulsivity, sexual abuse and self mutilation», Comprehensive Psychiatry, 1966, 37 (1), p.p.12-16.

3. Favazza, A.R.; Conterio, K., «Female habitual self-mutilators», Acta Psychiatrica Scandinavia, 1989, 79.

4. Alao, A.;Yolles J.C.; Armenta, W, «Genital self mutilation», Psychiatr Serv, 1999, 50, p.p.1362-1363.

5. Jelinek, E., La pianista. Barcelona, Mondadori, 1993.

6. Favazza, A.R., Bodies Under Siege: Self Mutilation and Body Modification in Culture and Psychiatry, Baltimore, John Hopkins University Press, 1987. 
7. Menninger, K., The man against himself. New York, Harcourt, Brace and World, 1938.

8. Sartre, J.P., El ser y la nada. Buenos aires, Losada, 1977

9. Mc Dougall, J., Teatros del cuerpo. Madrid, Julián Yébenes, 1991.

10. Laing, R.D., El yo dividido. México DF, Fondo de Cultura Económica, 1974.

11. Kierkegaard, S., La enfermedad mortal, Buenos Aires, Santiago Rueda Ed.,1941

12. Colina F., Escritos psicóticos. Madrid, Dor, 1996.

13. Céline, L.F., Viaje al fin de la noche. Barcelona, Edhasa, 1995.

14. Bulbena, A., «Psicopatología de la afectividad». En: Vallejo Ruiloba, J., Introducción a la psicopatología y a la psiquiatría. Barcelona, Masson, 1998.

15. Jaspers, K., Psicopatología general. México, Fondo de Cultura Económica, 1993.

16. Marty, P., El orden psicosomático. París, Payot, 1980.

17. Wilson K.G., Luciano M.C., Terapia de aceptación y compromiso (ACT). Un tratamiento conductual orientado a los valores. Madrid, Pirámide, 2002.

18. Skinner, B.F. Conducta verbal. México, Trillas, 1981.

19. Laplanche J., Pontalis J.B., Diccionario de psicoanálisis. Barcelona, Editorial Labor, 1974

20. Linehan, M.M., Cognitive behavioral treatment of borderline personality disorder. New York, Guilford, 1993.

21. Heller, A., Teoría de los sentimientos. Madrid, Fontamara, 1987.

22. Sartre, J.P., Bosquejo de una teoría de las emociones. Madrid, Alianza, 1971.

23. Piaget, J., Seis estudios de psicología. Barcelona, Seix Barral,1979.

24. Bateman, A.; Fonagy P., «Treatment of borderline personality disorder with psychoanalytically oriented partial hospitalization: a 18 month follow-up», Am J Psychiatry, 2001, 158, p.p. 36-42.

25. www.nobelprize.org/literature/ laureates/2004/jelinek-lecture-e.html

26. Merleau-Ponty, M., Fenomenología de la percepción, Barcelona, Península, 1975.

27. Stoller, R., Dolor y pasión, Buenos Aires, Manantial, 1998.

28. Deleuze, G., Presentación Sacher-Masoch, Madrid, Taurus, 1973.

29. Chasseguet-Smirgel, J., Ética y estética de las perversiones. Buenos Aires, Amorrortu, 1992.

30. Camus, A., Obras 1. Madrid, Alianza, 1991.

31. Freud, S., Obras Completas., Madrid, Biblioteca Nueva, 1972-1975.

32. www.brightlightsfilm.com/36/pianoteacher.html

33. Bertolucci, B., El último tango en París. Madrid, MGM/UA Home vides, 1990.

34. Kureishi. H., Intimidad, Barcelona, Anagrama, 1999.

35. Eguíluz I., Segarra R., Introducción a la psicopatología. Barcelona, Grupo Ars, 2005.

36. Kohut, H., La restauración del sí-mismo. Barcelona, Paidós, 1980. 
37. Kernberg, 0., Relaciones amorosas. Normalidad y patología. Buenos aires: Paidós, 1995.

38. Bettelheim, B., Symbolic Wounds», Glencoe IL, The Free Press, 1954.

39. Martínez Rodriguez, J.M., «Evolución del concepto de trastorno límite en el presente siglo». En: Psicosis y trastornos límites, Valladolid, Junta de Castilla y León, 1991.

40. Adorno, T., Quasi una Fantasia: Essays on Modern Music, London, Verso, 1992.

41. www.nietzscheana.com.ar

42. Nietzsche, F., Así habló Zaratustra. Madrid, Alianza Editorial, 1998.

43. www.nietzscheana.com.ar/vaihinger.htm

44. Pessoa., F., «Esta vieja angustia» en: Antología de Álvaro de Campos, Madrid, Alianza, 1987.

Rebeca García Nieto

P.I.R. del C.S.M. «Delicias»- Valladolid

Hospital Psiquiátrico «Doctor Villacián». Valladolid

Domicilio del centro

Paseo Juan Carlos I, No 18

47012- Valladolid

Tel.: $983-228044$

Fax: $983-228322$

Dirección personal

C/ García Morato 29-A, $2^{\circ} \mathrm{T}$

47007- Valladolid

Tel.: 983-132368

E-mail: rebecag2001@yahoo.es 